\title{
Yuji ljiri* \\ An Introduction to Corporate Accounting Standards: A Review
}

https://doi.org/10.1515/ael-2017-0058

\author{
Table of contents \\ 1 First section \\ 2 Second section \\ 3 Third section \\ 4 Fourth section \\ References
}

\section{Memorial Symposium for Professor Yuji ljiri}

1. “An Introduction to Corporate Accounting Standards: A Review” by Yuji ljiri, https://doi.org/ 10.1515/ael-2017-0058

2. "Axioms and Structures of Conventional Accounting Measurement" by Yuji ljiri, https:// doi.org/10.1515/ael-2017-0057

3. "Yuji ljiri: Accounting for a Better Society" by Shyam Sunder, https://doi.org/10.1515/ ael-2017-0045

4. “Yuji ljiri: On Accountability" by Jonathan Glover, https://doi.org/10.1515/ael-2018.0004

5. "Ijiri and His Influence in Japan" by Yoshitaka Fukui, https://doi.org/10.1515/ael-2017.0048

6. “The Double Entry System of Accounting” by John Fellingham, https://doi.org/10.1515/ ael-2018.0001

7. “An Interdisciplinary Journey with Professor Yuji ljiri” by Haijin Lin, https://doi.org/10.1515/ ael-2017.0056

\section{First section}

The term "classic" is defined to be a piece of work that has lasting significance or recognized worth and serves as an outstanding representative of its kind. An Introduction to Corporate Accounting Standards, by Paton and Littleton (1940), is an example of a work that fits this definition very well.

Reprinted with permission from Ijiri, Yuji. 1980. An Introduction to Corporate Accounting Standards: A Review. The Accounting Review 55 (4): 620-628. Copyright, 1980 American Accounting Association.

*Corresponding author: Yuji ljiri, Carnegie-Mellon University, Robert M. Trueblood Professor of Accounting and Economics, Pittsburgh, United States of America 
Published in 1940 by the American Accounting Association, the monograph has been reprinted 15 times. Over 60 thousand copies have been sold and, even 40 years after its publication, more than a thousand copies are sold every year. This longevity is a record for any research monograph in accounting.

Not only has the monograph had significant influence on accounting instructors, students, and practitioners on a number of issues dealing with accounting principles and standards, but also it seems to have set a pattern of reasoning in accounting and of research approaches that start with a set of basic assumptions. In this sense, the monograph is an outstanding representative of its kind.

Interesting details on the circumstances surrounding the preparation of this monograph are given in Zeff (1966). Briefly speaking, the project to develop a monograph on corporate accounting standards was commissioned by the Executive Committee of the American Accounting Association in 1938. Earlier, the Executive Committee developed and published, under the leadership of then president Eric L. Kohler, "A Tentative Statement of Accounting Principles Affecting Corporate Reports,” a five-page article listing key accounting principles (American Accounting Association, 1936). This Tentative Statement states the historical cost principle as the fundamental axiom of accounting. "Accounting is thus not essentially a process of valuation, but the allocation of historical costs and revenues to the current and succeeding fiscal periods. Each of the following propositions embodies a corollary of this fundamental axiom" (American Accounting Association, 1936, p. 188). It elaborates on a set of 20 propositions classified in three sections: costs and values, measurement of income, and capital and surplus.

Criticisms were raised extensively on the Tentative Statement immediately after its publication. "A careful study of the criticisms indicated that the earlier list of propositions ought to be supplemented by an outline of the basic theory which underlies the Tentative Statement. The authors undertook this task and the present monograph is the result," state Paton and Littleton in the preface to the monograph [p. ix].

It appears that the Executive Committee members as well as other members of the Association cooperated closely with the authors and provided significant inputs to the preparation of the monograph. In the foreword to the monograph, Howard C. Greer remarks, "The monograph is presented as a personal expression from the authors, but it undoubtedly is also an expression of the reasoned conviction, on almost every point covered, of the score or more men who have labored earnestly to make the preparation of this document possible" [p. vii]. 
Under these conditions, it is quite possible that the monograph turned out to be somewhat different from what the authors would have written had they been given an opportunity to develop the monograph freely without the task of supporting the Tentative Statement. However, any literary work is like the author's child; once published it acquires its own life that is independent of the author's. In this sense, what is reviewed here is the monograph itself and not necessarily the personal view of the two authors, which have been expressed and examined in numerous publications elsewhere. (For example, on their views on changing prices vis-à-vis historical cost, an excellent overview may be obtained from Zeff (1979); Paton's articles cited there and from Littleton (1961, pp. 287-372) which collects his writings on this subject.)

The monograph covers accounting concepts and standards under a unifying framework founded upon six basic assumptions of accounting. Key issues are organized systematically, starting with discussions on the need for accounting standards in Chapter 1 and on the underlying assumptions in accounting in Chapter 2. After these fundamentals are discussed, the monograph builds on them to deal with issues of "cost" in Chapter 3, "revenue" in Chapter 4, "income" in Chapter 5, and "surplus" in Chapter 6. Accounting standards are presented along with a network of theoretical concepts in a logical manner. The final chapter, Chapter 7, titled "Interpretation," which is somewhat more pragmatic in its reasoning relative to earlier chapters, discusses practical implications of some of the standards introduced earlier and encourages presentation of various kinds of interpretive financial information outside the main body of statements.

The monograph has been quoted extensively; the accounting framework and standards in the monograph have been introduced and examined in numerous textbooks and research monographs. However, strange as it may seem, there are not many review articles of the monograph. In fact, it has never been reviewed officially in the book review section of The Accounting Review. However, during the past 40 years, two articles on the monograph (Vatter, 1963; Wilcox, 1941) have appeared in The Accounting Review. In addition, shortly after the publication of the monograph, the American Institute of Certified Public Accountants appointed a three-member committee to review the monograph and published its report in The Journal of Accountancy (American Institute of Certified Public Accountants, Subcommittee of the Committee on Accounting Procedure, 1941). The most comprehensive treatment of the monograph, however, may probably be attributed to Kimura (1954), whose review and critique of the monograph from the viewpoint of the Marxian theory of value are almost as long as the original monograph. 


\section{Second section}

The monograph is one of the earliest attempts to develop a conceptual framework project which is now being developed by the Financial Accounting most recent being the conceptual framework project which is now being developed by the Financial Accounting Standards Board.

These attempts display a varying degree of tolerance for subjective information. While more recent attempts indicate a greater degree of tolerance for subjective information, the monograph strongly advocates "verifiable, objective evidence" as the basis for accounting information. This emphasis on verifiable, objective evidence seems to stem from a view of accounting that is founded on a notion of accountability.

In its opening section, the monograph sets a stage for subsequent development as follows:

The corporation's most important accounting responsibility ... [runs] to one or more groups or classes of detached investors, present and prospective, for each business unit. In reporting accounting data under these conditions, the desire to please or to defend may exercise more influence upon executive judgment than do objective circumstances. Accounting standards therefore become responsible for furnishing guideposts to fair dealing in the midst of flexible rules and techniques [p. 2].

It is mainly for this reason that "accounting standards should be systematic and coherent, impartial and impersonal, and in harmony with observable, objective conditions" [p. 1].

In formulating accounting concepts and standards, this accountabilityoriented view lays emphasis on the mechanisms for coping with possible conflicts of interests between the corporation and its investors in the flow of financial information. In contrast, in a decision-oriented view of accounting, which now widely accepted, emphasis is on the usefulness of information. Here, a corporation is depicted as an information supplier who is in full cooperation with its investors. Subjective information is welcome under this view and such qualitative characteristics as usefulness, relevance, and timeliness outweigh verifiability and objectivity of accounting information.

The need for verifiable, objective evidence is elaborated in Chapter 2 of the monograph as one of the six basic assumptions of accounting:

One of the important contributions made by professional auditing in its early development in Great-Britain was the emphasis placed upon objective evidence to support recorded transactions ... The dependability of the accounts was thus subject to the test of an examination of the origin of the transactions recorded. 
This emphasis upon objective evidence has never been weakened; in fact it has become stronger as complex business activities have increased and as business management and financial investment have drawn further apart. Verifiable, objective evidence has therefore become an important element in accounting and a necessary adjunct to the proper execution of the accounting function of supplying dependable information [p. 18].

Although verifiable, objective evidence is discussed as the last of the six basic assumptions of accounting, it seems to rank first among the six in terms of significance in guiding the contents of the monograph. The other five assumptions seem to be provided to support this key sixth assumption. It may, therefore, be interesting to trace the other five assumptions backward to examine their roles in supporting the sixth assumption.

In order to provide information on the enterprise's value and its income in a verifiable, objective manner, it becomes necessary to devise a means by which these values are determined by an accumulation of data on microscopic events. This is because objective means of weighing the value of an enterprise or its income en masse are difficult to develop.

One way to circumvent the lack of an objective scale large enough to measure the weight of an "elephant" might be to sum the weights of a large number of small objects which collectively push a boat down to the same water level as the elephant does. Thus, the fifth assumption, "effort and accomplishment," becomes a key ingredient in accounting in order to enable income determination on a piecemeal basis by matching efforts and accomplishments.

The underlying preference implicit in this approach appears to be the ageold doctrine of democracy, "safety in numbers." While a single appraiser may be able to develop information on the value of an enterprise, an inherent risk involved in relying upon such a single source of judgment might be considered far larger than the risk of relying upon a result derived by an accumulation of numerous small judgments, even if such an accumulation may be slow in reflecting the changing environment of the enterprise.

Since an effort and an accomplishment do not always match one to one, there must be a means by which a measurement associated with an effort is unbundled and regrouped based on its contribution to one or more accomplishments. Thus, the fourth assumption, "costs attach," becomes a necessary part of the framework in the monograph. It states that it is acceptable to divide and marshal costs to form new groups, "as if costs had a power of cohesion when properly brought into contact” [p. 13].

This in turn leads to the third assumption. There is normally a time lag between the time at which an effort is expended and the time at which its 
accomplishment is obtained. There must, therefore, be a means of dealing with pending efforts. The third assumption, "measured consideration," provides such a means. It states that such efforts be measured by their cost or "price aggregate" until the accomplishment is obtained. The term price aggregate is used in 'place of cost since price aggregate is a broader term than cost, covering both the cost and the benefit side of the resources.

The remaining two assumptions provide a foundation upon which the above four assumptions may take their effect.

The piecemeal approach to measurement would collapse unless the business conditions in the future are assumed to be similar to those observed in the past. The second assumption, "continuity of activity," is needed to make measured considerations meaningful in the above measurement framework.

Finally, for any measurement of an enterprise value or its income, the subject of measurement must be clearly identified. The first assumption, "the business entity," establishes the subject in accounting as primarily the business enterprise itself and not the shareholders. Even in defining net income, which is commonly considered to be a shareholder-based concept, the monograph leans toward a view that interest should be treated "as a charge to income rather than as a cost of revenue" [p. 44].

\section{Third section}

In this monograph, the basic principle of asset and liability valuation is developed upon historical cost. This historical cost principle is supported by such concepts as costs attach realization, and matching. Discussions of these concepts and their implications for accounting standards occupy a significant portion of the space in the monograph.

Justification for the historical cost principle comes in large part from the need for verifiable, objective evidence.

Although there is still some room for dispute over the determination of historical cost, it is based on a transaction that has actually occurred, and as such it is much more verifiable and objective than replacement cost or disposal value which are based on a hypothetical transaction that the enterprise might have or could have engaged in on the date of the financial statements.

In addition to verifiable, objective evidence, however, the monograph presents another reason for the use of historical cost. It emphasizes distributable nature of income; namely, to be eligible for income recognition, an asset must 
reach a form that can be made available for distribution to shareholders. A few different terms are used in the monograph to designate assets that satisfy this requirement, such as "near cash," "liquid or highly liquid assets" and "actual purchasing power." The monograph states, "appreciation makes available no additional liquid resources which may be used to meet obligations or make disbursements to investors" [p. 62].

This is a line of argument that is entirely different from the verifiability and objectivity issue. Even if there were a method of determining the market value of an enterprise verifiably and objectively, appreciation would not be a legitimate source of income under this view, since the asset has not reached the liquid state. Theoretically, this notion of an asset having to reach a liquid state before income is recognized, may be related to the labor theory of value which states that an increase in the value of a commodity, beyond the sum of values of inputs, occurs only after it has gone through a crucial test in the market, the socalled "salto mortale" (a deadly leap) of the commodity.

In discussing the realization concept, however, the monograph does not base its argument on any particular theory of value:

\footnotetext{
It is not necessary to assume a cost theory of value in order to explain the concept that costs cohere ...

If cost of production were to represent "value," it should include an amount for the added utility given to the product by the process of business operation itself. But this is not attempted. The producer may think that utility has been added and that the product is worth more than the sum of the several costs; but he does not know. One's own judgment of added utility is not conclusive; the test comes when a sale is made [pp. 13-14].
}

In addition to the verifiability-objectivity issue and the distributable income issue, the monograph touches upon a third line of argument for historical cost which comes from the notion of accountability. For a proper functioning of accountability, it is essential to have a system by which charges and discharges of accountability are properly recorded and reported. This means that accounting records must keep step with the actual production and other operating processes. "When production activity effects a change in the form of raw materials by the consumption of human labor and machine-power, accounting keeps step by classifying and summarizing appropriate portions of materials cost, labor cost, and machine cost so that together they become product-costs" [p. 13].

Unlike market value data which require no information on historical movements of goods and services, historical cost determination weaves through physical movements of goods and services. Therefore, in addition to representing assets, liabilities, revenues, and expenses as such, historical cost data in 
financial statements serve as control accounts for voluminous records on physical movements of resources in the past.

While the rationality of historical cost accounting is not limited to these three points (see Ijiri (1980) for further discussions on the subject), they are certainly the most important aspects of historical cost accounting.

Based on these arguments, the monograph advocates a rather strict adherence to a valuation principle based on historical cost. After careful examination, the monograph presents arguments against the cost-or-market method, standard costing, and recognition of imputed interest on equity, appreciation of assets, and accretion of natural resources. Even the case for price level adjustment was considered not very strong at that time, although this may be quite natural since prices in 1936-40 were very stable after having dropped by a third from their level in 1920. The only significant exception to the strict adherence to historical cost that is accepted in the monograph is the case of a reorganization under which assets may be revalued.

In this monograph, determination of historical cost is based on actual cash paid at the time of exchange, or if cash is not exchanged immediately, it is based on implied cash, the amount of cash that would be needed to settle the exchange at the time of the exchange. Hence, receivables and payables must be discounted to present values. Exchanges of non-monetary assets are valued by estimating implied cash, and so are donated or discovered assets. Cost that is capitalized should be total cost, including even selling as well as general and administrative cost, though accounting practice has never accepted this approach. Direct costing is rejected because it covers only a part of total cost. The cost principle is analogously applied to the assumption of liabilities and issuance of stock, both of which must be based on actual cash received and not par value.

Capitalization is subject to two tests: (i) cost must be bona fide, thus excluding abnormal waste, for example, and (ii) the asset must have future benefits. As soon as it is determined that the asset does not have assumed future benefits, the loss should be recognized immediately as a charge against current income. Thus, while the cost-or-market method is rejected, the test of benefits must be applied continuously. The distinction is important. An asset has use value in addition to exchange value, and insofar as the benefits from the intended use of the asset are at least as great as the book value, its exchange value being lower than its book value is not a cause for a write-down.

It should be carefully noted, however, that the strict adherence to historical cost argued in the monograph applies only to the information in the main body of financial statements. The monograph places no limit on the kinds of information that may be provided outside the financial statements. "Accounting should 
set no limits upon the supplying of pertinent information. By means of footnotes, text to accompany account titles, parenthetic figures, extra columns, and similar devices, significant estimates of current values and other collateral data may be shown in their relation to the primary figures" [p. 126]. The monograph encourages disclosure of such market-based data as long as they are disclosed as supplementary information together with proper labels.

While supplying pertinent information to investors is encouraged, the monograph stresses that such information should not be a substitute for information that is to be derived under the objective framework described in the monograph, because objectively determined historical cost information is vitally needed as a benchmark. "If, however, such values are reported as supplementary data on special occasions as needed, the objectively determined quantities are preserved with illuminating additions. Indeed, the value data themselves are likely to be of little use unless reported in conjunction with the known 'basing point,' cost” [p. 126].

In addition to arguments for historical cost and related accounting concepts and standards, the monograph also presents arguments in favor of the allinclusive income statement as well as strict separation of earned surplus from paid-in surplus. "A definite position is taken here to the effect that all determinants of income in the broadest sense - including unusual and irregular factorsshould be reported in the income statement before the net results are passed to the stock-equity section of the balance sheet" [p. 102], the monograph concludes. On the separation of paid-in surplus and earned surplus, it states, "paid-in or capital surplus may not be used as a source of earned surplus. Likewise no part of earned surplus should be incorporated in reported paid-in capital, except as such surplus has been converted into capital by legal process of capitalization” [p. 106].

Although the monograph is intended to "weave together the fundamental ideas of accounting rather than to state standards as such" [p. ix], in a number of places it gives prescription of accounting standards, perhaps as examples of implications of the fundamental concepts. Unfortunately, space does not allow an examination of these standards here in this article.

\section{Fourth section}

When the monograph is compared with subsequent attempts to establish an accounting framework, a significant difference may be noted, namely the revival of the balance-sheet orientation since the publication of the monograph. 
The approach in the monograph starts out with cost and revenue and then goes on to income and surplus. Assets and liabilities play only a secondary role in the monograph. In contrast, the present-day view of an accounting framework is centered on definitions and measurements of assets and liabilities, from which revenues, expenses, gains and losses are developed as derivative concepts and measurements. (See, for example, Financial Accounting Standards Board (1979)).This may be in part related to the increasing emphasis that has been placed on market values of assets in recent years, although historical cost financial statements are still presented as the primary financial statements.

Underscoring the income-statement orientation, the monograph states that the primary purpose of accounting is "the measurement of periodic income by means of a systematic process of matching costs and revenues" [p. 123], and "Earning power - not cost price, not replacement price, not sale or liquidation price - is the significant basis of enterprise value. The income statement, therefore, is the most important accounting report" [p. 10].

This view of accounting, which originates in Schmalenbach (1919), was given a new thrust by Paton and Littleton as a result of their framework of accounting based on a set of assumptions centered on verifiability and objectivity. In effect, the monograph has provided assurance to accountants that it is perfectly all right to record historical costs, add them, allocate them, match them with revenues, and list unmatched ones on a balance sheet, without being bothered by market values, as long as costs are bona fide and are supported by future benefits.

This assurance that cost-based income determination is theoretically sound is perhaps the central reason for its having been so enthusiastically received by accountants over the past four decades. Accountants needed justification for the process they use, other than saying that things are as they are because they are so by convention. The monograph supplied this needed justification based on a theoretical framework of accounting without ever resorting to the notion of accounting conventions.

As a matter of fact, the term "convention" rarely appears in the monograph. It would have been easy for the authors to make reference to accounting conventions, saying that certain standards must be accepted because they exist by convention. But perhaps it was considered to be theoreticians' defeat to have to resort to justification by convention; it seems that the monograph was written with a firm belief that accounting practice could be and should be justified on a theoretical ground, based on an accounting theory that is "a coherent, coordinated, consistent body of doctrine which may be compactly expressed in the form of standards if desired" [p. ix]. This is what made the monograph different from a mere compendium of accounting standards and 
what made this a model for later attempts by many other authors in developing an accounting framework.

Finally, it should also be noted that this monograph reflects the difficult environment in which accountants must operate.

Mathematicians are lucky, in a sense, because they have a set of rigorous constraints that bind their reasoning. The rocky terrain, so to speak, in which they must operate is in a way fortunate for them, because once a path is found everyone follows it, for there are very few alternatives available. This enables them to say what is right and what is wrong.

Even economists are fortunate because they have production technologies and market mechanisms which cannot be changed overnight. These technical constraints existing in the real world bind their thinking considerably, since these constraints are something that cannot be changed even if everyone agrees to change.

Compared with these, the environment in which we accountants live may be likened to a vast, flat plain. We can go north, south, east, or west as we wish. Things can be changed by agreement or by edict literally overnight, as we have seen in recent years. This may sound like a luxury; but on the contrary this is the very source of the battle in which all of us accountants are forced to engage, because we must "justify" what we do with very few sources of justification.

Periodic income determination is a good example. Determination of the income of an enterprise whose life is, say, two years is easy if income over the two year period is to be determined. However, to determine income in each of the two years is just as difficult, and in fact just as arbitrary, as determining which of the two clapped hands made the noise. Choosing one out of many, equally acceptable alternatives is difficult enough; justifying the choice is often impossible.

Nevertheless, society demands a determination of periodic income and its justification. "The flow of business activity has a long continuity; the ultimate outcome of the activities lies in the future. But decisions cannot await the ultimate outcome; management, investors, government, all of the interested parties, need 'test readings' from time to time in order to gauge the progress made" [p. 14-15], the monograph asserts. Since such test readings often affect someone's interest, justification of the method used in deriving the readings is demanded.

In this sense, it may be said that we accountants are fundamentally destined to be "free." We suffer from this freedom. We want to be bound by theories, principles, standards, and the like. Yet, they are so fragile relative to the weight often placed upon them. 
This monograph is a monument of the battle which our predecessors fought courageously. Its true contribution, however, can be understood only by those who appreciate this difficult environment in which accountants must operate.

Original Acknowledgment: This article was solicited by the Book Review Editor in commemoration of the fortieth anniversary of the publication by the American Accounting Association of An Introduction to Corporate Accounting Standards, by W. A. Paton and A. C. Littleton. The author is indebted to Stephen A. Zeff, Taminosuke Nishimura, Vernon K. Zimmerman, George Mead, and Donald H. Skadden for valuable pieces of information on the background of the monograph and relevant references; he is also grateful for insightful comments on an earlier draft of this article by Stephen A. Zeff and Katherine Schipper. Manuscript received and accepted March, 1980.

\section{References}

American Accounting Association. (1936, June). A tentative statement of accounting principles affecting corporate reports. The Accounting Review, 187-191.

American Institute of Certified Public Accountants, Subcommittee of the Committee on Accounting Procedure. (1941). Report of the subcommittee appointed to study 'An introduction to corporate accounting standards' by W. A. Paton and A. C. Littleton. Journal of Accountancy, 48-57.

Financial Accounting Standards Board, Elements of financial statements of business enterprises, Exposure Draft of Proposed Statement of Financial Accounting Concepts (FASB, 1979).

Ijiri, Y. (1980). Historical cost accounting and its rationality. Research Monograph (Canadian Certified General Accountants Association.

Kimura, W. (1954). Kaikei gaku kenkyu (studies in accounting theory). Yuhikaku (in Japanese). Littleton, A. C. (1961). Essays on accountancy. Urbana, IL: University of Illinois Press.

Paton, W. A. \& Littleton, A. C. (1940). Monograph No.3. An introduction to corporate accounting standards. American Accounting Association (AAA).

Schmalenbach, E. (1919). Grundlagen dynamischer Bilanzlehre, 1959, translated in English by G. W. Murphy and K. S. Most. Dynamic accounting. London: Gee and Co.

Vatter, W. J. (1963, July). $\sum_{i=1}^{i=22}\left(M_{3}\right)_{i}-$ An Evaluation. The Accounting Review, 470-477.

Wilcox, E. B. (1941). Comments on 'An introduction to corporate accounting standards'. The Accounting Review, 75-81.

Zeff, S. A. (1966). The American Accounting Association: Its first 50 years. American Accounting Association (AAA).

Zeff, S. A. (1979). Paton on the effects of changing prices on accounting: 1916-55. Zeff, S. A., J. Demski \& N. Dopuch (Eds.), Essays in honor of William A. Paton: pioneer accounting theorist (pp. 91-137). Ann Arbor: Graduate School of Business Administration, The University of Michigan. 